\title{
ASSOCIATION BETWEEN PREMORBID ADJUSTMENT AND FACIAL EMOTIONS RECOGNITION IN SCHIZOPHRENIA
}

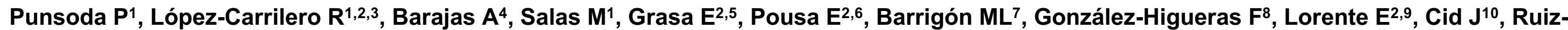

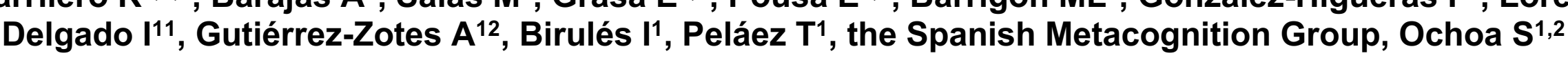

1 Parc Sanitari Sant Joan de Déu; 2 Investigación Biomédica en Red de Salud Mental, CIBERSAM; 3 Institut de Recerca Sant Joan de Déu; 4. Centre d'Higiene Mental Les Corts; Departament de Psicologia Clínica i de la Salut, Facultat de Psicologia, UAB; 5 Department of Psychiatry, Hospital de la Santa Creu i Sant Pau, Institut d'Investigació Biomèdica-Sant Pau (IIB-Sant Pau), UAB; 6 Salut Mental Parc Taulí, Hospital Universitari UAB, Neuropsiquiatria i Addicions, Hospital del Mar, IMIM (Hospital del Mar Medical Research Institute); 7 Department of Psychiatry, IIS-Jimenez Diaz Foundation; Autonoma University, Madrid; Psychiatry Service, Area de Gestión Sanitaria Sur Granada; 8 Comunidad Terapéutica Jaén Servicio Andaluz de Salud; 9 Psychiatry Service, Hospital Clínico Universitario de Valencia;

10 Mental Health \& Addiction Research Group, IdiBGi, Institut d'Assistencia Sanitària, Girona; 11 Unidad Salud Mental Comunitaria Málaga Norte, UGC Salud Mental Carlos Haya, Servicio Andaluz de Málaga; 12 Institut Pere Mata, Reus.

Objectives: The aim of this study is to determine the relationship between the premorbid adjustment (PA) and deficits in facial recognition (FR), in persons with first-episode psychosis (FEP).

Background and aims: FR is a fundamental cognitive process linked to emotions processing, both usually impaired in persons with schizophrenia (1). Studies have reported impaired affect identification as a prominent clinical feature in schizophrenia. Furthermore, deficits in premorbid social and academic performance have been suggested to be good predictors of severity of positive symptoms, social knowledge, and negative emotion recognition deficit (2). This study aimed to conduct additional research by assessing FR deficits and PA in persons with FEP

Materials and methods: The sample of FEP consisted of 33 patients (age range: 18-45) with a diagnosis of schizophrenia, psychotic disorder not otherwise specified, delusional disorder, schizoaffective disorder, brief psychotic disorder or schizophreniform disorder, whose symptoms began in less than five years. Level of functioning was assessed with the Premorbid Adjustment Scale (PAS), and the Faces Test was used in order to assess the FR. Pearson correlation was used to relate PA and FR.

Results: Deficits in basic-level Faces Test were significantly linked to poorer academic performance $(p=0,046)$ and premorbid sociability $(p=0,043)$. Specifically, deficits in FR expressing anger and guilt, were statistically related to poorer academic performance ( $p=0,011$ and $p=0,049$, respectively).

\begin{tabular}{|c|c|c|c|c|}
\hline $\begin{array}{c}\text { Correlations } \\
{ }^{*} \text { Correlation is significant at the } \\
0,05 \text { level (2-tailed) }\end{array}$ & $\begin{array}{c}\text { Faces Test } \\
\text { (Basic-level) }\end{array}$ & $\begin{array}{c}\text { Faces Test } \\
\text { (Complex-level) }\end{array}$ & $\begin{array}{c}\text { Faces Test } \\
\text { (Total) }\end{array}$ \\
\hline PAS Sociability & $\begin{array}{c}\text { Bilateral } \\
\text { Significance }\end{array}$ &, 043 &,- 202 &,- 264 \\
\hline PAS Academic & Pearson Correlation &,$- 350^{*}$ &,- 122 &, 137 \\
\hline & $\begin{array}{r}\text { Bilateral } \\
\text { Significance }\end{array}$ &, 046 &, 498 &,- 220 \\
\hline
\end{tabular}

\begin{tabular}{|c|c|c|c|c|c|c|c|c|c|c|c|}
\hline \multirow[b]{2}{*}{$\begin{array}{l}\text { Anger } \\
\text { face }\end{array}$} & \multicolumn{10}{|c|}{ Two-Sample t-Test for Equal Means } & \multirow[b]{2}{*}{$\begin{array}{c}\text { Bilateral } \\
\text { Significance }\end{array}$} \\
\hline & Recognition & $\begin{array}{c}\text { Not } \\
\text { recognition }\end{array}$ & $\begin{array}{c}\text { Mean } \\
\text { differences }\end{array}$ & $\mathrm{t}$ & $\begin{array}{c}\text { Bilateral } \\
\text { Significance }\end{array}$ & $\begin{array}{l}\text { Guilt } \\
\text { face }\end{array}$ & Recognition & $\begin{array}{c}\text { Not } \\
\text { recognition }\end{array}$ & $\begin{array}{c}\text { Mean } \\
\text { differences }\end{array}$ & $\mathrm{t}$ & \\
\hline $\begin{array}{c}\text { Mean } \\
\text { Academic } \\
\text { PAS }\end{array}$ &, 2500 & 6111 & ,36111 & 2,712 & 011 & $\begin{array}{c}\text { Mean } \\
\text { Academic } \\
\text { PAS }\end{array}$ & ,2466 & ,4549 & ,20821 & 2,049 &, 049 \\
\hline $\begin{array}{l}\text { Mean } \\
\text { Social } \\
\text { PAS }\end{array}$ & ,3202 & ,4688 & , 14859 & 1,155 &, 257 & $\begin{array}{l}\text { Mean } \\
\text { Social } \\
\text { PAS }\end{array}$ & ,3082 & ,4813 & ,17306 & 1,905 & ,066 \\
\hline
\end{tabular}

Conclusions: Deficits in negative emotion recognition are linked to poorer academic premorbid performance. These results suggest that emotion recognition should be addressed in early interventions.

References

1. Healey, K.M., Bartholomeusz C.F. y Penn, D.L. (2016). Deficits of social cognition in first episode psychosis: A review of the literature. Clinical Psychology Review, 50: 108-137.

2. Dewangan, R.L. y Singh, P. (2018). Premorbid Adjustment in Predicting Symptom Severity and Social Cognitive Deficits in Schizophrenia. East Asian Arch Psychiatry, 28: 75-9. 